\title{
Time Domain Analysis of the Ventilation around the Partial Immersed Propeller Using Sliding Mesh Method
}

\author{
Ehsan Yari
}

\section{Department of Maine Engineering, Maleke Ashtar University of Technology; ehsanyari11@gmail.com}

\begin{tabular}{|c|c|}
\hline ARTICLE INFO & ABSTRACT \\
\hline $\begin{array}{l}\text { Article History: } \\
\text { Received: } 29 \text { Dec. } 2016 \\
\text { Accepted: } 15 \text { Mar. } 2017\end{array}$ & $\begin{array}{l}\text { In this paper a computational method is presented for predicting the unsteady } \\
\text { hydrodynamic forces acting on partial immersed propeller (SPP). In order to } \\
\text { simulate the unsteady viscous flow around a SPP, a Reynolds-Averaged }\end{array}$ \\
\hline $\begin{array}{l}\text { Keywords: } \\
\text { Partial Immersed Propeller } \\
\text { RANS Method } \\
\text { Sliding Mesh } \\
\text { Unsteady Forces/Moments. }\end{array}$ & $\begin{array}{l}\text { Navier-Stokes (RANS) solver is used. The time-accurate calculations are } \\
\text { made by applying the sliding mesh method. Structured and unstructured mesh } \\
\text { techniques are used. The method is applied in the case of the straight } \\
\text { condition. Hydrodynamic coefficients are compared with experimental data } \\
\text { and show good agreement between them. Also, ventilation pattern, pressure } \\
\text { distribution and unsteady forces/moments on key blade of SPP is presented } \\
\text { and discussed. }\end{array}$ \\
\hline
\end{tabular}

\section{Introduction}

Among many propulsors, SPP practically reveals that provide highest efficiency for planing crafts. It operates behind the hull to generate thrust for overcoming the resistance at design speed. It is working in unsteady and multiphase flow which is very complicated. Many problems effect on the hydrodynamic performance. Due to suction on the blade and near the free surface, cavitation and ventilation may create, especially at low speed/heavy conditions.

The SPP efficiency is primarily attributed to the reduction of appendage drag, since the most of the propeller assembly is elevated above the water [1]. The cavitation elimination and replacing it with ventilation is among the SPP benefits; the cyclic blade entry from air into water creates a ventilated zone around the propeller that almost completely prevents the occurrence of vapor cavitation. One of the SPP application disadvantages is that the per-formance prediction method is still under develop-ment. Moreover the SPP design is often executed in a trialand-error basis, although SPPs are used largely in the boat racing community.

The first research activity on SPPs was conducted by Shiba [2].In the research, 2D section of surface propeller with different profiles and the various parameters affecting the ventilation phenomenon were investigated experimentally. During 1970s to 1990s, several experimental tests were conducted on ventilation parameters and their effects were evaluated on thrust average loss and its efficiency by Wang [3], Olofsson [4], Rose \& Kruppa [5-6-7], Nozawa \&
Takayama [8], Ferrando et al [9-10]. Olofsson carried out very deeply by experimental tests for the forces and flow characteristics of the SPP on his $\mathrm{PhD}$ thesis [4]. Ferrando et al. have efficiently carried out experimental tests and obtained effect of parameters such as immersion depth, axial shaft slope, Weber number and pitch ratio on the hydrodynamic characteristics of the SPPs [9-11].

Numerical simulations of the SPP employed by Caponnetto and his results compared with Olofsson experimental data had good agreement in terms of blade forces during a rotation cycle [12]. Young \& Kinnas [13] extended a 3D boundary element method which was developed in the past to predict unsteady sheet cavitation on conven-tional fully submerged propellers so that the per-formance of super-cavitating and SPP can be predicted. Then, Koushan presented his research about total dynamic loadings of ventilated pro-pellers, and showed that fluctuations during one ventilation cycle can range from 0 to $100 \%$ of the average force of a non-ventilated propeller [14]. Bin et al was simulated using a mass transfer cav-itation model and the k-w SST turbulence model. Their numerical model reasonably predicted experimental data for the unsteady cavitation pat-terns as well as the oscillation amplitudes of the dominant pressure components [15].

Amromin [16] has applied various CFD models such as RANS method to model the cavitating detachment point and finally has shown the numerical result validation compared with experimental data. Numerical approach predicted the hydrodynamic characteristics of the SPP [17]. Once the critical 
advance coefficient found based on the Weber number and propeller pitch ratio in the transition mode, then the potential based boundary element method (BEM) applied to predict the hydrodynamic characteristics of the SPP.

Following Koushan's research, numerical simula-tion was performed for different types of propeller ventilation by Califano et.al [18]. The research aimed to analyze the ventilation mechanism. The commercial RANS code was used to solve the viscous, incompressible, two-phase flow. In terms of both thrust forces and air content, the present analysis shows a satisfactory agreement with the filtered experimental data during the first half revolution. Different types of propeller ventilation classification and ventilation inception mechanism based on several experiments analysis were investigated by Kozlowska et.al [19]. Accordingly, three different types of ventilation inception mechanisms were observed. Vinayan \& Kinnas solved the flow field around a ventilated two-dimensional surface piercing hydrofoil and propellers, using a robust nonlinear boundary element method. Results are presented for the fully wetted and ventilated cases with and without the effects of gravity, simulating the effect in various Froude numbers [20]. A series of four-bladed propellers of the surface piercing type was developed to design a SPP for a given operating condition by Misra et.al [21]. In the research, the best performance at all immersions was obtained from the propeller, using wedge shaped sections with the trailing edge inclined at $60^{\circ}$ to the hori-zontal axis. Only a propeller series with four blades has been developed in this work. Numerical analysis of surface piercing propeller using RANS method was extracted by Himei [22]. In the study, first an analysis program based on potential flow theory for supercavitating propeller (fully wetted code) was used for surface piercing propeller. Based on obtained results, RANS simulations have good agreement with experimental ones.

The motivation of the present research is to ana-lyze the flow behavior around SPP, using CFD, AnsysFluent 14.5, based on RANS method. The propeller Analysis has been executed in unsteady open water condition under the free surface effect. All calculations were done at zero shaft yaw and inclination angle. The amounts of force/ moment components of key blade in a SPP revolution are calculated and compared with experimental data. Finally the results of pressure coefficients and ventilation pattern on the propeller and key blade are discussed.

\section{Hydrodynamic characteristics of the SPP}

For a SPP, not only the geometrical parameters are important but also the physical working conditions are essentially significant on the hydrodynamic performance. Generally, the thrust and torque of the SPP are the geometrically functions and the physical parameters are function of the advance velocity ratio $J$ , Froude number $F_{n}$, Reynolds number $R_{n}$, cavitation number $\sigma$ and the Weber number $W_{n}$. Beside them, the shaft inclination angle $\psi$ and the immersion ratio $I$ are additional parameters influence on the hydrodynamic behavior of the SPPs. Thus, the hydrodynamic characteristics of the SPP can be expressed as

$$
\begin{aligned}
& K_{T}=f\left(J, F_{n}, R_{n}, \sigma, \psi, I, W_{n}\right) \\
& K_{Q}=f\left(J, F_{n}, R_{n}, \sigma, \psi, I, W_{n}\right) \\
& \eta=f\left(K_{T}, K_{Q}, J\right)
\end{aligned}
$$

Where

$$
F_{n}=n \sqrt{\frac{D}{g}}, R_{n}=\frac{n D^{2}}{v}, W_{n}=\sqrt{\frac{(n D)^{2} h}{\kappa}}
$$

and $v$ and $\kappa$ are the kinematic viscosity and kinematic capillarity. Model experiments indicate that at sufficiently high values of Froude number the effect of the Froude number vanishes i.e. for a Froude number greater than 4 , there is practically not affected on the hydrodynamic characteristics of the SPP.

The hydrodynamics characteristics of a SPP are defined as follow:

$$
K_{T}=\frac{T(\text { thrusi) }}{\rho n^{2} D^{4}}, K_{Q}=\frac{Q(\text { torque })}{\rho n^{2} D^{5}}, \eta=\frac{K_{T}}{K_{Q}} \cdot \frac{J}{2 \pi}
$$

where $\mathrm{K}_{\mathrm{T}}, \mathrm{K}_{\mathrm{Q}}$ and $\eta$ are equal $\mathrm{KF}_{\mathrm{X}}, \mathrm{KM}_{\mathrm{X}}$ and Eta respectively. Other coefficients in $\mathrm{y}$ - and z-directions $\left(\mathrm{KF}_{\mathrm{y}}, \mathrm{KF}_{\mathrm{z}}, \mathrm{KM}_{\mathrm{y}}\right.$, and $\left.\mathrm{KMz}\right)$ are defined like Eqs. (1) and (2).

\section{Governing equations}

The continuity equation can be written as follow:

$$
\frac{\partial \rho}{\partial t}+\nabla \cdot(\rho \vec{u})=S_{m}
$$

The $\mathrm{S}_{\mathrm{m}}$-source term- is the mass added to the continuous phase which is obtained from the dispersed second phase. The momentum conservation equation in an inertial reference frame is described by

$$
\frac{\partial}{\partial t}(\rho \vec{u})+\nabla \cdot(\rho \vec{u} \cdot \vec{u})=-\nabla p+\nabla \cdot(\rho \bar{\tau})+\rho \vec{g}+\vec{F}
$$

Where $\mathrm{p}$ is the static pressure, $\bar{\tau}$ is the stress tensor, and $\rho \vec{g}$ and $\vec{F}$ are the gravitational body force and external body forces, respectively. $\vec{F}$ also contains other model-dependent source terms such as porousmedia and user defined sources. The standard $k-\varepsilon$ model is a model based on model transport equations for the turbulence kinetic energy $k$ and its dissipation rate $\varepsilon$. The model transport equation for is derived from the exact equation, while the model transport equation for was obtained using physical reasoning and bears little resemblance to its mathematically exact counterpart. In the derivation of the $k-\varepsilon$ model, the assumption is that the flow is fully turbulent, and 
the effects of molecular viscosity are negligible. The standard $k-\varepsilon$ model is therefore valid only for fully turbulent flows. The turbulence kinetic energy, $k$ and its rate of dissipation, $\varepsilon$ is obtained from the following transport equations [23]:

$$
\begin{aligned}
& \frac{\partial}{\partial t}(\rho k)+\frac{\partial}{\partial x_{i}}\left(\rho k u_{i}\right)=\frac{\partial}{\partial x_{i}}\left[\left(\mu+\frac{\mu_{t}}{\sigma_{k}}\right) \frac{\partial k}{\partial x_{i}}\right] \\
& +G_{k}+G_{b}-\rho \varepsilon-Y_{M}+S_{k} \\
& \frac{\partial}{\partial t}(\rho \varepsilon)+\frac{\partial}{\partial x_{i}}\left(\rho \varepsilon u_{i}\right)=\frac{\partial}{\partial x_{i}}\left[\left(\mu+\frac{\mu_{t}}{\sigma_{\varepsilon}}\right) \frac{\partial \varepsilon}{\partial x_{i}}\right] \\
& +C_{1 \varepsilon} \frac{\varepsilon}{k}\left(G_{k}+C_{3 \varepsilon} G_{b}\right)-C_{2 \varepsilon} \frac{\varepsilon^{2}}{k}+S_{\varepsilon}
\end{aligned}
$$

In these equations, $G_{k}$ represents the generation of turbulence kinetic energy due to the mean velocity gradients, calculated as described in modeling turbulent production in the $k-\varepsilon$ Models. $G_{b}$ is the generation of turbulence kinetic energy due to buoyancy, calculated as described in effects of buoyancy on turbulence in the $k-\varepsilon$ models. $Y_{M}$ represents the contribution of the fluctuating dilatation in compressible turbulence to the overall dissipation rate, calculated as described in effects of compressibility on turbulence in the $k-\varepsilon$ Models. $C_{1 \varepsilon}, C_{2 \varepsilon}$ and $C_{3 \varepsilon}$ are constants. $\sigma_{k}$ and $\sigma_{\varepsilon}$ are the turbulent Prandtl numbers for $k$ and $\varepsilon$, respectively. $S_{k}$ and $S_{\varepsilon}$ are user-defined source terms.

The volume of fluid (VOF) model may consider two or more immiscible fluids by solving a single set of momentum equations and tracking the volume fraction of each of the fluids throughout the domain. The stalking of the interface between the phases is achieved by the solution of a continuity equation for the volume fraction of one (or more) of the phases. This equation has the following form:

$$
\begin{aligned}
& \frac{1}{\rho_{q}}\left(\frac{\partial}{\partial t}\left(\alpha_{q} \rho_{q}\right)+\nabla \cdot\left(\alpha_{q} \rho_{q} \vec{u}_{q}\right)\right. \\
& \left.=S_{\alpha_{q}}+\sum_{p=1}^{n}\left(\dot{m}_{p q}-\dot{m}_{q p}\right)\right)
\end{aligned}
$$

Where $\dot{m}_{q p}$ is the mass transfer from $\mathrm{q}$ phase to $\mathrm{p}$ phase and $\dot{m}_{p q}$ is the mass transfer from $\mathrm{p}$ phase to $\mathrm{q}$ phase. $S_{\alpha_{q}}$ is zero. The momentum equation is solved with a second order upwind scheme. A no-slip condition is set on all elements of the SPP (propeller, hub, boss and shaft).

\section{Results and Discussion \\ 4.1. SPP-841B Propeller}

In this paper, numerical simulations of SPP-841B propeller model are selected. This propeller was profoundly tested by Olofsson [6], so all experimental data are available. Propeller is immersed one-third of the propeller diameter $(\mathrm{I}=\mathrm{h} / \mathrm{D})$, rotated by revolution rate $(\mathrm{n})$ and velocity enters to the propeller $\left(\mathrm{V}_{\mathrm{A}}\right)$, as shown in Figure 1.

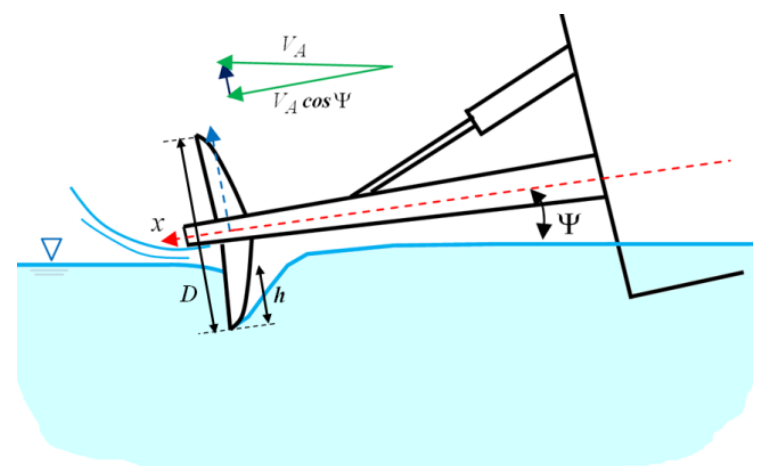

Figure 1. Definitions of shaft inclination angle $\Psi$ and immersion ratio $\mathrm{I}=\mathrm{h} / \mathrm{D}$.

Characteristics of the propeller are determined at various advance velocity coefficient $\mathrm{J}\left(=\mathrm{V}_{\mathrm{A}} / \mathrm{nD}\right)$. Particulars of the propeller model of the SPP-841B are given in Table 1.

Table 1 Particulars of propeller model of the SPP-841B [4]

\begin{tabular}{lcc}
\hline Parameter & Symbol & Value \\
\hline Diameter $(\mathrm{mm})$ & $\mathrm{D}$ & 250 \\
\hline Hub diameter $(\mathrm{mm})$ & $\mathrm{d}$ & 85 \\
\hline Pitch at 0.7 radius $(\mathrm{mm})$ & $\mathrm{P}$ & 310 \\
\hline Hub-diameter ratio & $\mathrm{d} / \mathrm{D}$ & 0.34 \\
\hline Pitch-diameter ratio at 0.7 radius & $\mathrm{P} / \mathrm{D}$ & 1.24 \\
\hline Expanded Area ratio & $\mathrm{A}_{\mathrm{E}} / \mathrm{A}_{0}$ & 0.58 \\
\hline Number of blades & $\mathrm{Z}$ & 4 \\
\hline Immersion ratio & $\mathrm{h} / \mathrm{D}$ & 0.33 \\
\hline Rotation & & R.H. \\
\hline
\end{tabular}

The flow behavior on a SPP is always in unsteady condition and then numerical simulation must be solved marching in time, during a full rotation of the propeller. Free surface changes consideration in SPP rotation is an important and effective parameter in propeller analysis. In the research the computational 
domain is composed by two main zones. Internal zone (rotational) is considered as a cylinder around SPP and rotates with propeller within the external zone. External zone (Fixed) is a rectangular cube and its dimensions are selected so that the side walls have no effect on the flow behavior around the SPP. At each time step the internal zone is rotated a small amount. The axis passing through the propeller shaft is intended as the SPP rotation axis. Computational fluid variables are interpolated at the interface surfaces between internal and external zones at each time step. The propeller geometry has been produced in home code. The grid inside each zone is produced by the combination of structured and non-structured mesh. To increase the accuracy of calculations, boundary layer mesh on the propeller surfaces, hub, boss, and shaft is generated. In the sliding mesh technique, two cell zones are used, which are the stationary zone and moving zone. These cells zones are connected with each other through non-conformal interfaces. Each cell zone is bounded by an interface zone where it meets the opposing cell zone. The interface zones of adjacent cell zones are associated with one another to form a mesh interface. The two cell zones will move relative to each other along the mesh inter-face. During the calculation, all of the boundaries and the cells of a given mesh zone move together in a rigidbody motion and the cell zones slide (that is, rotate or translate) relative to one another along the mesh interface in discrete steps. As the mesh motion is updated in time, the non-conformal interfaces are likewise updated to reflect the new positions in each zone and fluid can pass from one zone to the other. Mesh generation around the SPP-841B propeller and computational domain are shown in Figure 2. In the present study, the distance of first grid from the blade section in boundary layer is about $0.06 \mathrm{~mm}$ and number of layers is set to 10 . The total number of cell is about 3.8 million and it is good enough for the present calculation results.

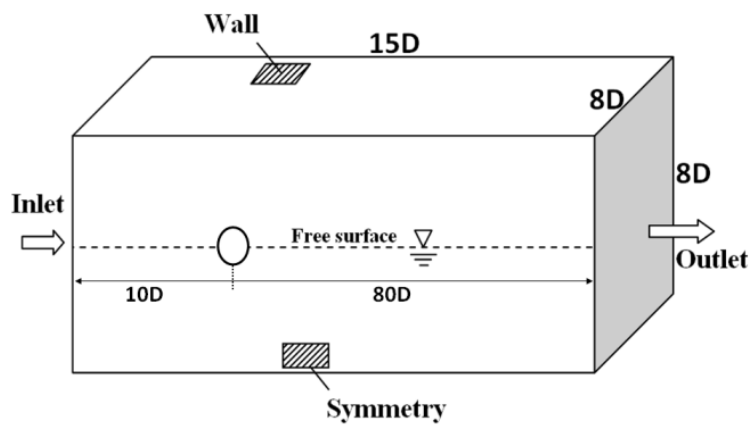

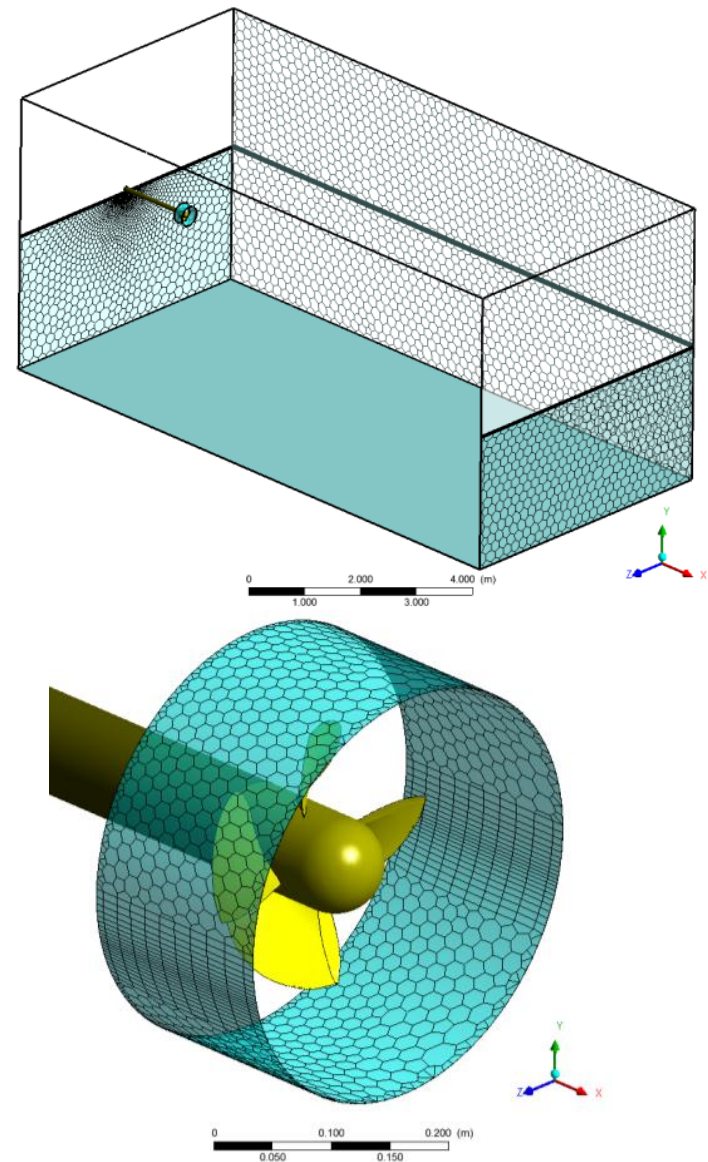

Figure 2. Computational domain and boundary conditions.

\subsection{Grid study}

To study the computational grid generated around the propeller, thrust hydrodynamic coefficient $\left(\mathrm{K}_{\mathrm{t}}\right)$ in a cycle of rotating propeller in five different modes of computational cell numbers is investigated. According to the Figure 3, after the number of 4.2 million grids doesn't have a significant change in the results.

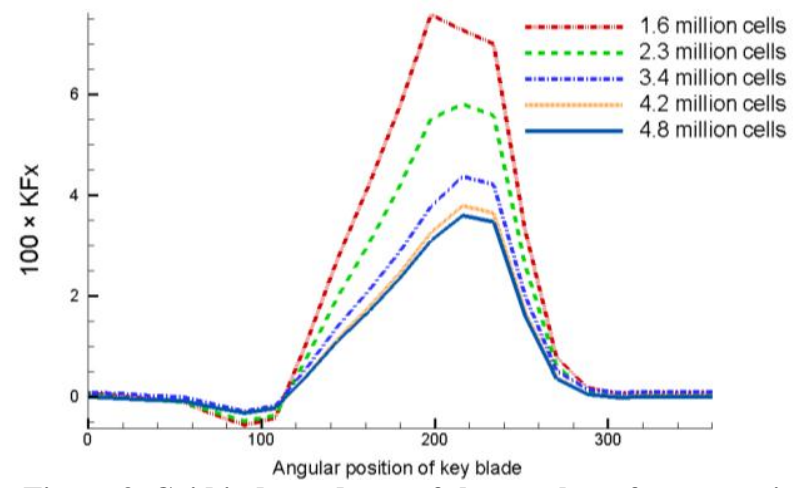

Figure 3. Grid independency of the number of computational elements on the $\mathrm{KF}_{\mathrm{X}}$.

To validate the numerical results, graph of $\mathrm{Y}^{+}$on the propeller are presented in Figure 4. As it can be seen the maximum $\mathrm{Y}^{+}$is under 190 . 

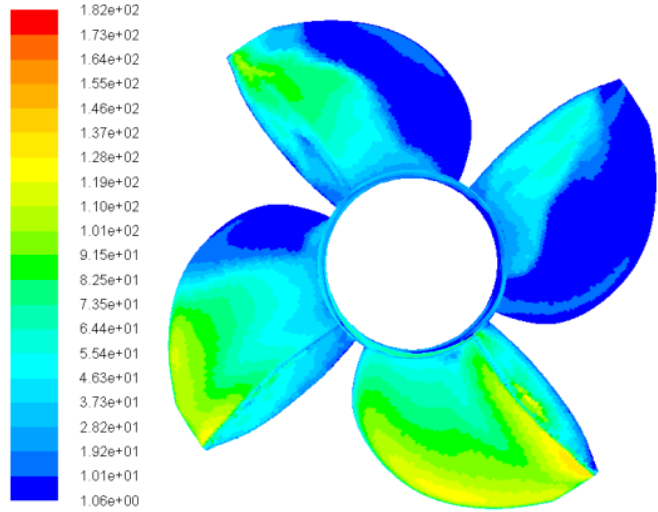

Face
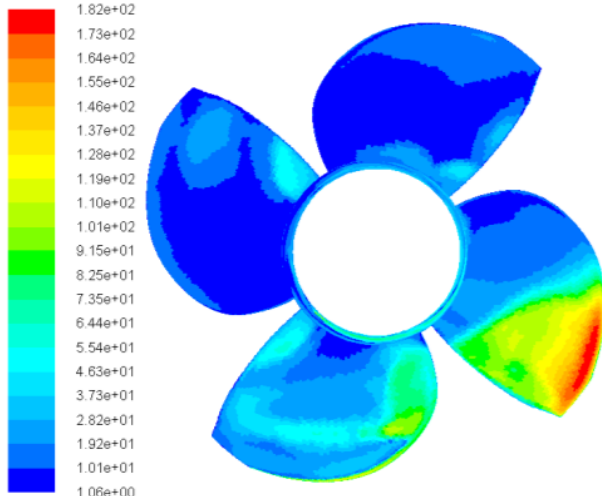

Back

Figure 4. Contours of $\mathrm{Y}+$ on back and face side of the SPP.

\subsection{Hydrodynamic analysis}

Figures 5 is presented comparison of the thrust and torque coefficients and efficiency against advance coefficient, respectively. The numerical results are in good agreements with experimental measurements. Since the maximum efficiency is usually related to the design point of the propeller, therefore, at this point the maximum coincidence can be seen between the numerical and experimental results. In low advance coefficient, less than number one, greater difference can be seen that is related to SPP operation in heavy condition. In the low advance ratios the trailing wake of the SPP is very unstable and therefore its modeling is complex and requires more research and development. Figure 6 presented relative percentage error versus advance ratio between numerical results and experimental measurements.

For considering the pressure distribution on the SPP, contour of the total pressure on back and face of the propeller and key blade is presented in Figure 7 at $\mathrm{J}=0.8$.
The comparisons of force/moment coefficients components at $\mathrm{J}=0.8$ is shown in Figure 8. As shown in this figure, the numerical results are relatively good agreement with the experimental results. Figure 9 shows the ventilation pattern on the back side of the key blade at three angular positions during one cycle. The results are obtained for $\mathrm{J}=0.8$ and as it can be seen, there are fairly good conformity between experimental observation and numerical contours. This adaptation is reduced in low advance coefficient due to the propeller operation in heavy and unstable conditions. Figure 10 shows the pressure coefficient on the key blade at different positions. The pressure at the back is almost constant due to the ventilation.

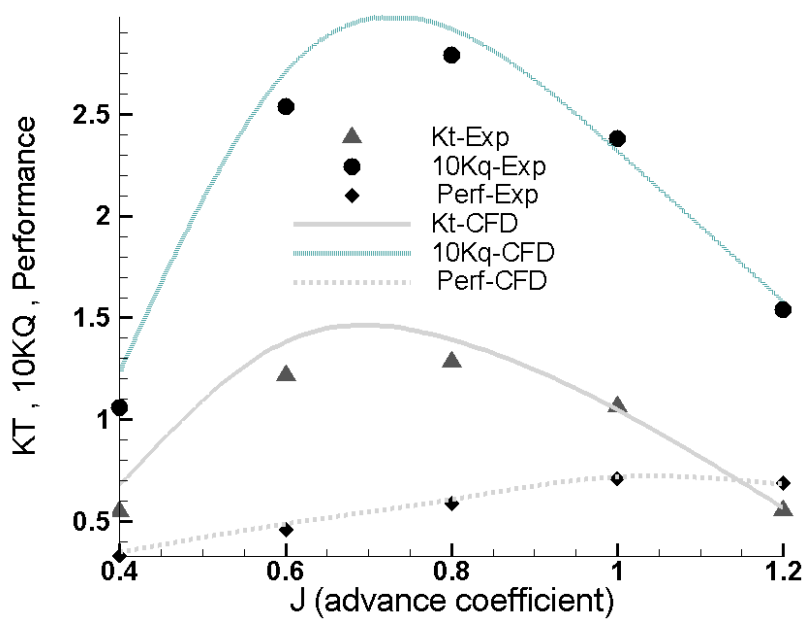

Figure 5. Comparison of the thrust and torque coefficients $\left(K_{T}\right.$, $\left.10 K_{Q}\right)$

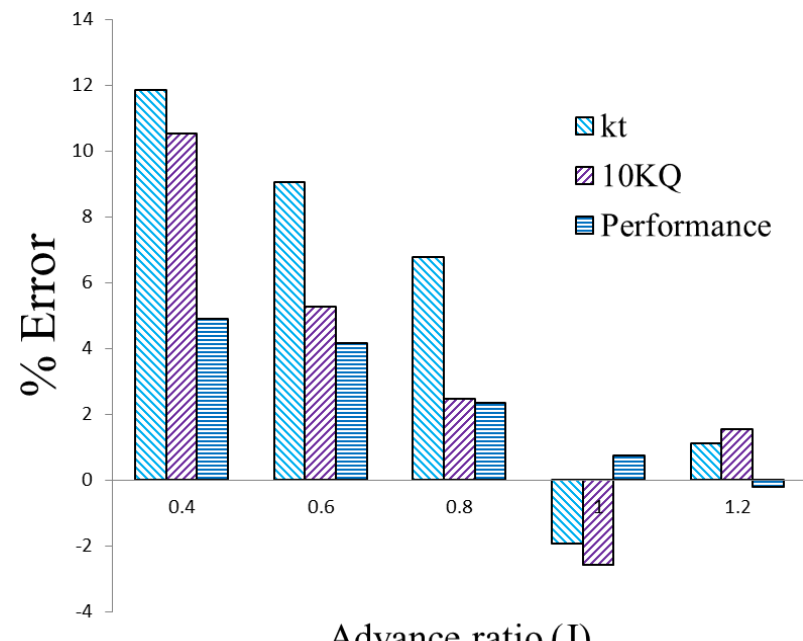

Advance ratio $(\mathrm{J})$

Figure 6. Relative percentage error versus advance ratio 


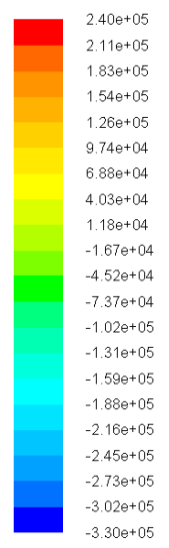

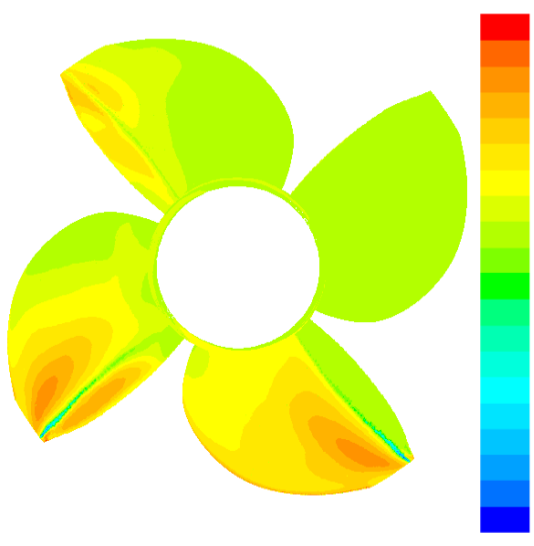

Face side

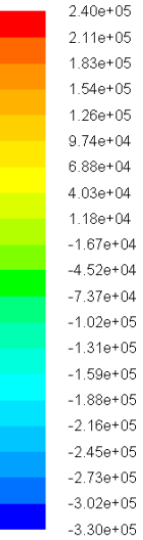

Back side

Figure 7. Contour of the total pressure on face and back side of SPP.
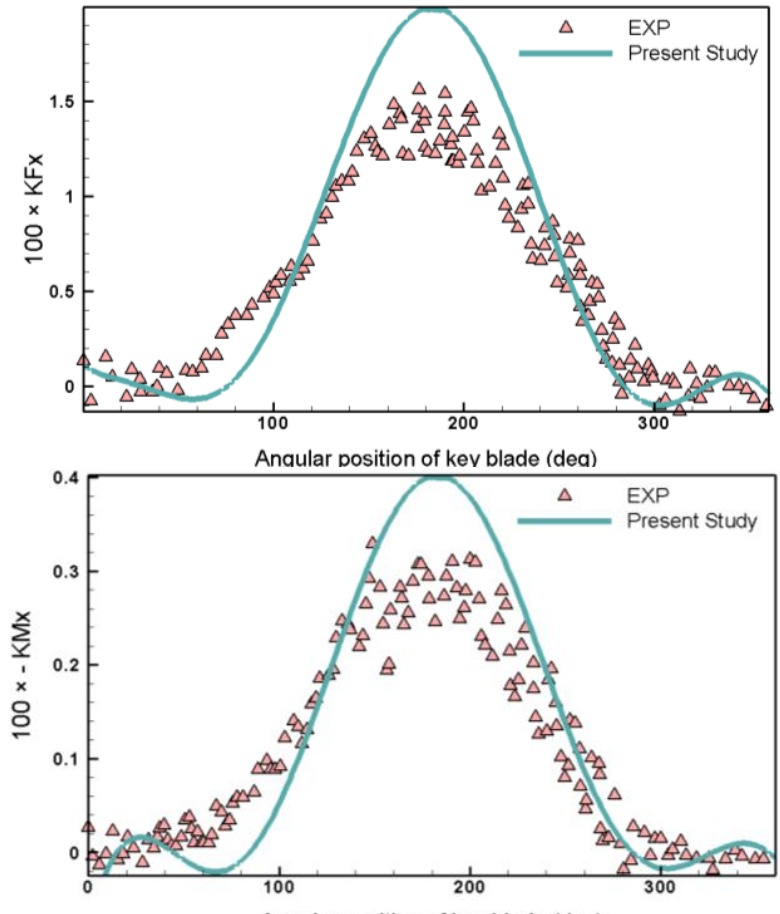

Anqular position of key blade (dea)

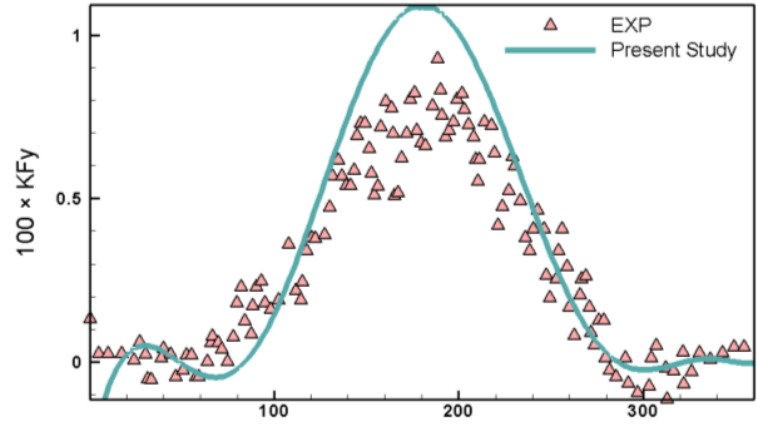

Angular position of key blade (deg)

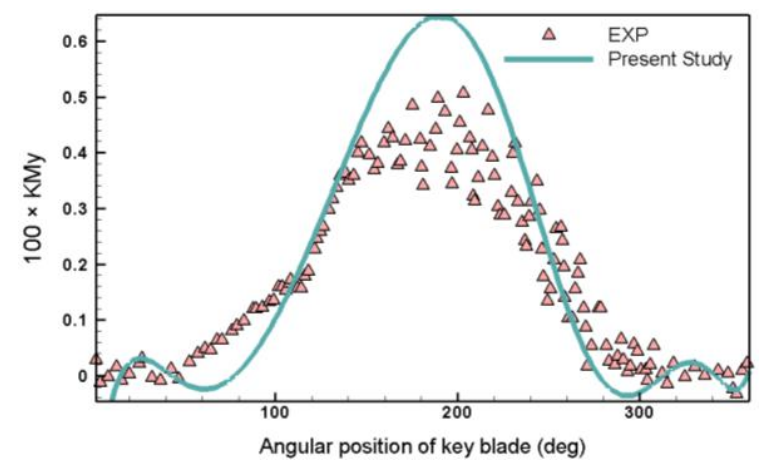

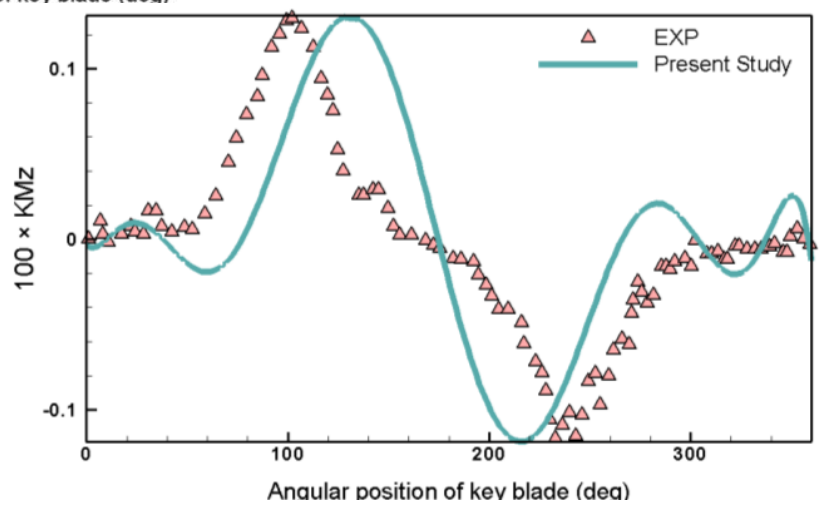

Figure 8. Comparison between the simulated and measured rotational fluctuation of 6-component force/moment versus angular position of key blade $(\mathrm{J}=\mathbf{0 . 8})$. 


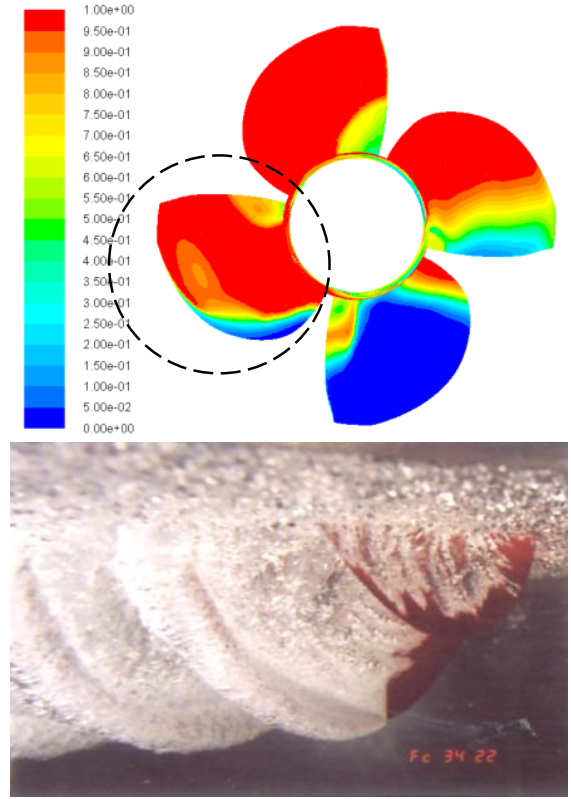

(a) $(\theta)=120 \mathrm{deg}$
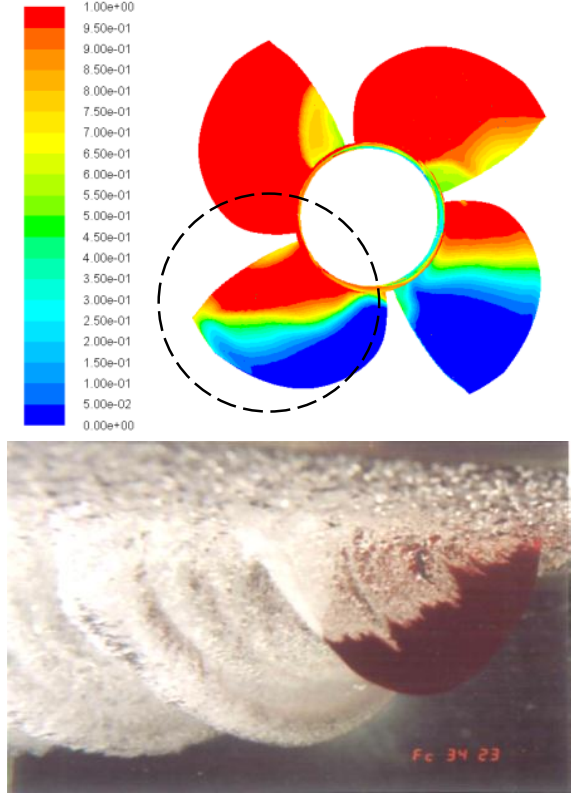

(b) $(\theta)=150 \mathrm{deg}$
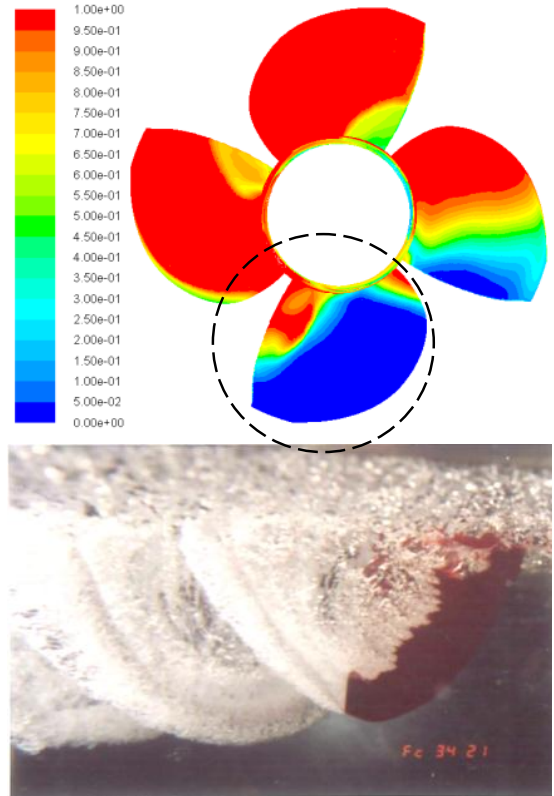

(c) $(\theta)=180 \mathrm{deg}$

Figure 9. Comparison of the ventilation patterns between simulated results and the experimental observed at three angular positions of key blade back side $(\mathrm{J}=\mathbf{0 . 8})$
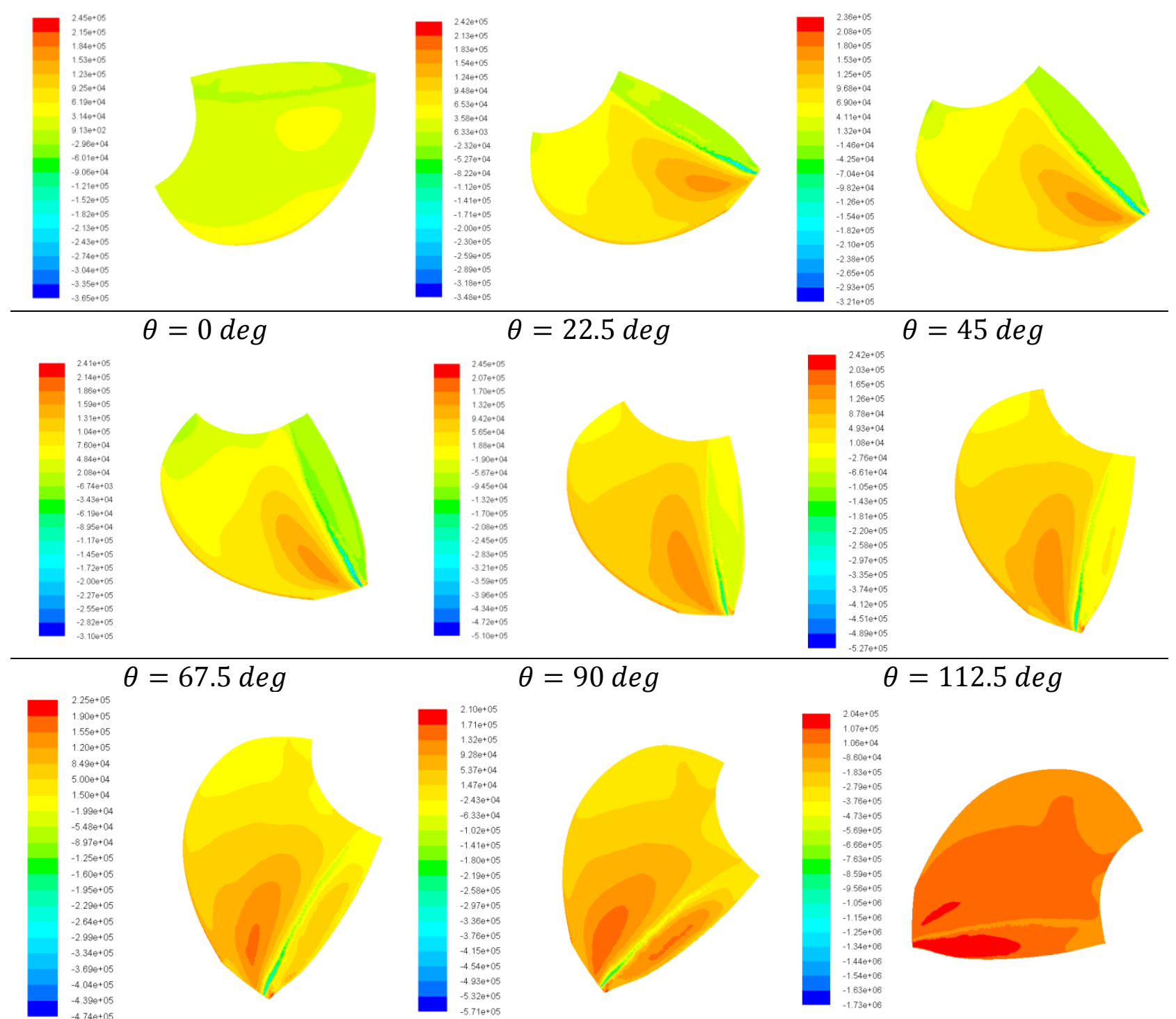

$$
\theta=67.5 \mathrm{deg}
$$

$550+05$

$1.20 \mathrm{\theta}+05$
$8.49 \mathrm{\theta}+04$
$500 \mathrm{\theta}+04$

$500+04$

$-1.99 \mathrm{e}+04$

$480+0$

$-8.97 \mathrm{e}+04$
$-1.25 \mathrm{e}+05$
$-1.60 \mathrm{e}+05$

$-1005 \theta+05$
$-299+05$

- $640+05$

$-2.99 e+05$
$-34 \mathrm{e}+05$

$-3.69+05$

$-4.39 \theta+05$
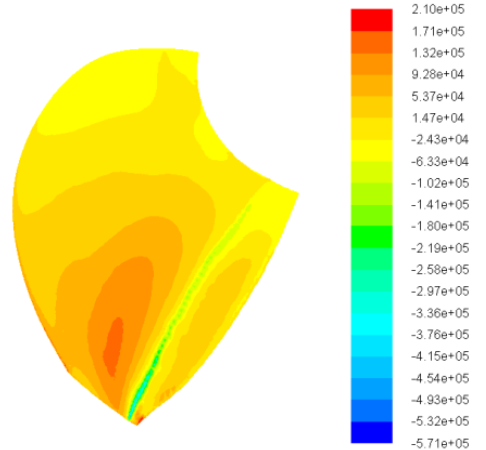

$\theta=90 \mathrm{deg}$

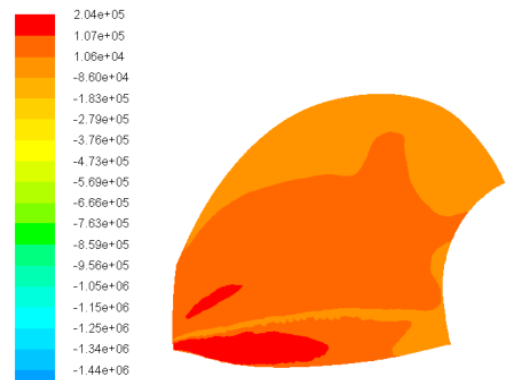

$\theta=135 \mathrm{deg}$

$\theta=157.5 \mathrm{deg}$

$\theta=180 \mathrm{deg}$ 


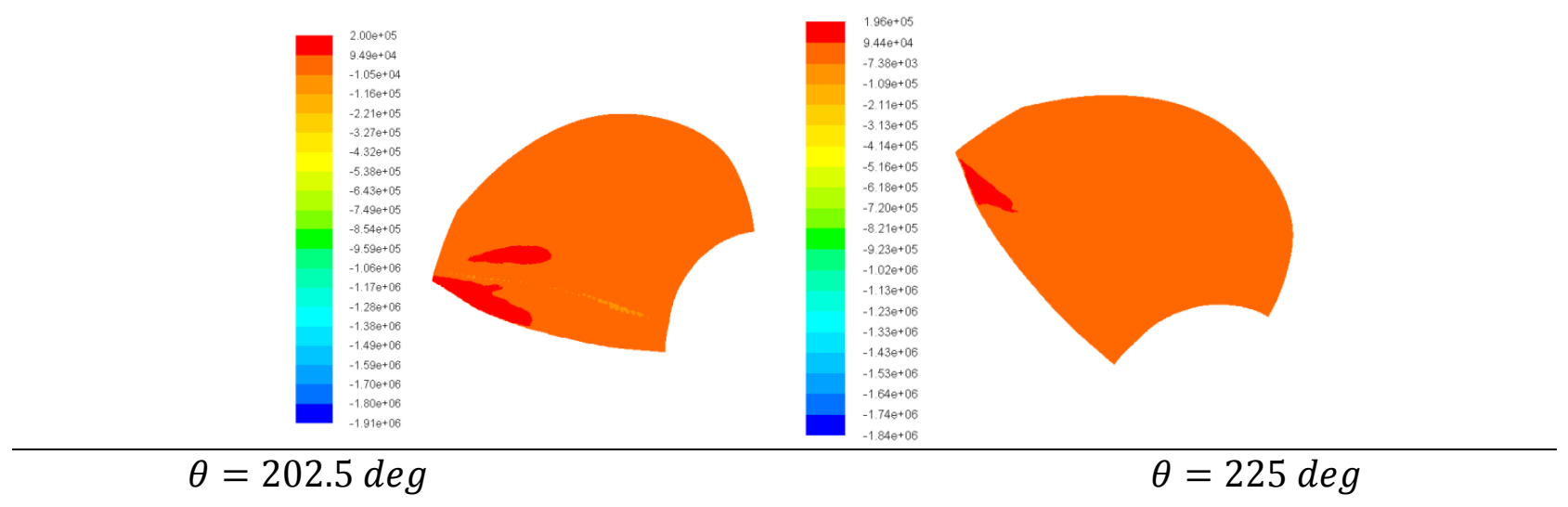

Figure 10. Contour of the total pressure on key blade in angular position of key blade face side $(\mathrm{J}=0.8)$.

\section{Conclusions}

In this article, numerical analysis of the SPP in unsteady flow under open flow conditions is investigated. A finite volume method based on RANS solver is used to analyze the ventilation pattern, the pressure, and hydrodynamic forces. With regard to the numerical results obtained from the calculations, the following conclusions can be offered:

- There is a good agreement between numerical results and experimental data for open water characteristics of the propeller. Small relative error is found at high advance velocity coefficient $(\mathrm{J})$ while higher error is at lower $\mathrm{J}$ due to the propeller operation in heavy conditions.

- Comparisons between numerical and experimental data show that there is relatively good agreement for the forces and moments versus angular rotation of the blade during one cycle.

- Ventilation pattern shows that there are fairly good conformity between present results and observed. The pressure coefficient at the back is almost constant due to the ventilation.

- In the low advance ratios of the SPP because of instability in the form of vortices and strong spray of water the better turbulence model and more accurate modeling is required.

- Cup-shaped of near trailing edge has significant impact on the amount of pressure on the front surface of the blade; therefore, the thrust of the propeller. The study of fluid flow when leaving the cup near trailing edge of propeller blade is similar supercavitating flows.

\section{References}

1. Young, Y. L., and Kinnas, S. A., (2004), Performance Prediction of Surface- Piercing Propellers, Journal of Ship Research, Vol. 28: pp. 288-304.

2. Shiba, H, (1953), Air-Drawing of Marine Propellers, Technical Report 9, Transportation Technical Research Institute.
3. Wang, D., (1977), Water Entry and Exit of a Fully Ventilated Foil, Journal of Ship Research, 21:pp. 4468.

4. Olofsson, N, (1996), Force and Flow Characteristics of a Partially Submerged Propeller, $\mathrm{PhD}$ thesis, Department of Naval Architecture and Ocean Engineering, Chalmers University of Technology (CUT), Goteborg, Sweden.

5. Rose, J. C. and Kruppa, C. F. L, (1991), Surface Piercing Propellers - Methodical Series Model Test Results, In FAST'91, Norway.

6. Kruppa, C. F. L, (1992), Testing Surface Piercing Propellers, In Hydrodynamics: Computations, Model Tests, and Reality, pp. 107-113.

7. Rose, J. C., Kruppa, C. F. L., and Koushan, K, (1993), Surface Piercing Propellers - Propeller/Hull Interaction, In FAST'93, pp.867-881, Japan.

8. Nozawa, K., Takayam, N., (2002). Experimental study on propulsive performance of SPP, Proceeding of the KSNAJ, No. 237.

9. Ferrando M., Scamardella A. Bose N. Liu P. Veitch B., (2002), Performance of family of surface piercing propellers, Royal Institution for Naval Architects (RINA) Transactions Part A.

10. Ferrando M., Viviani M., Crotti S., Cassella P., Caldarella S., (2006), Influence of Weber number on surface piercing propellers model tests scaling, Proceedings of $7^{\text {th }}$ International Conference on Hydrodynamics (ICHD), Ischia.

11. Ferrando M., Crotti S., Viviani, M., (2007), Performance of a family of surface piercing propeller, the $2^{\text {nd }}$ International Conference on Marine Research and Transportation (CMRT2007), Ischia, Naples, Italy.

12. Caponnetto M., (2002), RANSE Simulations of Surface Piercing Propellers, Rolla Research.

13. Young, Y. L. Kinnas. S. A, (2003), Analysis of Supercavitating and Surface-Piercing Propeller Flows via BEM, Computational Mechanics 32, 269280, Springer-Verlag.

14. Koushan, K, (2004), Environmental and Interaction Effects on Propulsion Systems Used in Dynamic Positioning, an Overview, Proceedings of $9^{\text {th }}$ International Symposium on Practical Design of Ships 
and other Floating Structures PRADS 2004, LübeckTravemünde, Germany.

15. Bin Ji, Xianwu Luo, Yulin Wu, (2014), Unsteady cavitation characteristics and alleviation of pressure fluctuations around marine propellers with different skew angles, Journal of Mechanical Science and Technology", Volume 28, Issue 4, pp1339-1348.

16. Amromin E., (2014), Development and validation of computational fluid dynamics models for initial stages of cavitation, J. Fluids Eng 136(8), 081303 (May 19, 2014) (8 pages).

17. Ghassemi, H., (2009), Hydrodynamic Characteristics of the Surface-Piercing Propellers for the Planing Craft, Journal of Marine Science and Application, December 2009, Volume 8, No 4, pp 267-274.

18. Califano, A., Steen S., (2009), Analysis of Different Propeller Ventilation Mechanisms by Means of RANS Simulations, First International Symposium on Marine Propulsors, SMP'09, Trondheim, Norway, June.
19. Kozlowska A. M., $\square$ Wöckner K., Steen S., $\square$ Rung T., Koushan K., Spence S., (2009), Numerical and Experimental Study of Propeller Ventilation, First International Symposium on Marine Propulsors, SMP'09, Trondheim, Norway, June.

20. Vinayan, V., Kinnas, S. A., (2008), Numerical Modeling of Surface Piercing Hydrofoils and Propellers, In Proceedings of the 27th Symposium on Naval Hydrodynamics.

21. Misra S. C., Gokarn R. P., Sha O. P., Suryanarayana C., Suresh R. V., (2012), Development of a Four-Bladed Surface Piercing Propeller Series, Naval Engineers Journal, No. 124(4), 105-138.

22. Himei, K., (2013), Numerical Analysis of Unsteady Open Water Characteristics of Surface Piercing Propeller, 3rd International Symposium on Marine Propulsors SMP'13, Launceston, Tasmania, Australia, 292-297.

23. Launder B. E. and Spalding D. B., (1972), Lectures in Mathematical Models of Turbulence, Academic Press, London, England. 